\title{
O PODCAST MUNDARÉU COMO UMA EXPERIÊNCIA DE ANTROPOLOGIA PÚBLICA
}

\author{
Soraya Fleischer ${ }^{1}$ \\ Daniela Tonelli Manica ${ }^{2}$
}

\section{Introdução}

Em geral, a presença pública da Antropologia em mídias mais convencionais é atribuída primeiramente à Margaret Mead. Sem dúvidas, no contexto dos EUA, ela teve um papel enorme de divulgação e popularização da Antropologia. Mas, em termos de rádio, Bronislaw Malinowski foi "um dos primeiros antropólogos a atuar como convidado de programas de rádio". Ele fez uma apresentação no British Broadcasting Corporation (BBC) sobre o tema da Ciência e Religião em 1930, "o que levou a um programa em seis partes sobre o tema do casamento em 1931, com a posterior publicação como fascículos na revista da BBC The Listener" (Sanjek, 2015: 302). E este foi só o início porque E. Evans-Pritchard, M. Gluckman e E. Leach tiveram participações continuadas na rádio da BBC. Falar sobre nossas pesquisas, nos mais variados meios de comunicação, não é uma prática nova na Antropologia, mas esteve presente desde seus primórdios, por diferentes motivos e motivações. $^{3}$

O Mundaréu, um podcast de Antropologia, é também motivado pela comunicação pública dessa área de conhecimento. Almejamos falar mais e para mais gente sobre Antropologia. Acreditamos que há muita pesquisa antropológica acontecendo, dentro e fora da universidade, que tem produzido resultados que podem ser úteis para uma audiência mais ampla e para a produção de políticas públicas mais sensíveis e inclusivas. Divulgar esses

\footnotetext{
${ }^{1}$ Universidade de Brasília, Brasil. E-mail: soraya@unb.br ORCID id: https://orcid.org/0000-0002-7614-1382

${ }^{2}$ Universidade Estadual de Campinas, Brasil. E-mail: dtmanica@unicamp.br ORCID id: https://orcid.org/0000-0001-8014-9996

${ }^{3}$ Conhecer mais sobre a história da participação de antropólogos e, principalmente, antropólogas tendo atuações em mídias radiofônicas é um tema de pesquisa que deve ser levado adiante, assim como a participação pública dos/as antropólogos/as brasileiros/as em meios de comunicação.
} 
resultados, e traduzir e popularizar a área são os dois principais objetivos desse podcast. Ao escolher a mídia do podcasting para deliberadamente vocalizar a Antropologia, acreditamos estar tornando-a mais aberta e pública.

Em 2018, como uma iniciativa conjunta entre o Departamento de Antropologia da Universidade de Brasília e o Laboratório de Estudos Avançados em Jornalismo da Universidade Estadual de Campinas, começamos a idealizar o Mundaréu. Passamos 2019 construindo o projeto e, em novembro de 2019, lançamos o seu primeiro episódio. Até esse mês de novembro de 2020, produzimos oito episódios na primeira temporada ${ }^{4}$, e acabamos de iniciar a segunda ${ }^{5}$. No intervalo, produzimos a série "Mundo na sala de aula", na qual o material produzido anteriormente foi revisitado pelos/as estudantes da equipe. Elas/es remontaram e reapresentaram esse conteúdo, em nove episódios que visam pensar questões colocadas pelos próprios estudantes em relação à formação em Antropologia e o uso de podcasts em sala de aula.

O Mundaréu é um projeto coordenado e apresentado por nós duas, Daniela e Soraya, com o apoio direto de uma equipe de 13 estudantes de graduação e pós-graduação da Unicamp e da UnB, e de financiadores como a FAPESP, Proec e Sae/Unicamp, CNPq, PIBIC e $\mathrm{CEAD} / \mathrm{UnB}^{7}$.

Neste texto, nossa proposta é pensar a Antropologia pública a partir especificamente do formato do Mundaréu. Vamos argumentar que esse formato parte, aprofunda e problematiza o conceito de "mutualidade". Para tanto, primeiro, vamos apresentar o formato do Mundaréu; em seguida, trazer algumas acepções para o conceito "mutualidade"; e, por fim, refletir sobre sua rentabilidade em termos de efeitos epistemológicos na confecção de uma Antropologia pública.

\footnotetext{
${ }^{4}$ https://mundareu.labjor.unicamp.br/episodios/primeira-temporada/

${ }^{5} \mathrm{https}: / /$ mundareu.labjor.unicamp.br/episodios/segunda-temporada/

${ }^{6} \mathrm{https}: / /$ mundareu.labjor.unicamp.br/series/mundo-na-sala-da-aula/

${ }^{7}$ Para uma apresentação sobre a metodologia de trabalho e as etapas de produção do Mundaréu, ver Fleischer e Couto (2020).
} 


\section{Formato}

Quando desenhamos o Mundaréu, queríamos evitar formatos que já estavam em largo uso, com excelentes resultados e boa consolidação. A saber, por um lado, a entrevista longa e em profundidade com uma única antropóloga convidada; e, por outro, a mesa redonda com uma conversa mais espontânea com várias pesquisadoras sobre um mesmo tema. Queríamos inventar outro formato que pudesse, de algum modo, servir como uma marca do Mundaréu, com um perfil que ajudasse o público a lembrar-se do programa. No formato, procurávamos uma identidade para o programa, que também ajudasse a informar sobre o tipo de Antropologia na qual estamos apostando. A escolha do formato, portanto, tem inspiração e reverberação teóricas, metodológicas, éticas e políticas.

Foi nesse esteio que pensamos em trazer para a conversa uma antropóloga e uma de suas interlocutoras centrais. As duas a um só tempo, face a face, reencenando de alguma forma como podem acontecer os encontros cotidianos entre elas quando estão juntas no campo (da antropóloga) e na vida (da interlocutora). Estamos priorizando a díade fundante da Antropologia, considerando a centralidade que a relação, o contato entre duas pessoas adquiriu, historicamente, para a realização do trabalho de pesquisa na área ${ }^{8}$. Trouxemos para estúdio a dupla básica que permite que um diálogo antropológico possa começar a existir.

Este formato não é novo, claro. A questão da autoria e da autoridade na escrita etnográfica foi problematizada, e vários formatos alternativos foram experimentados (e parcialmente mapeados, em Clifford, 1998). De lá para cá, livros e artigos científicos foram escritos a várias mãos (Kopenawa e Albert, 2015; Guérios, 2015; Fonseca e Garrido, 2018; Manica, Goldenberg e Asensi, 2018), filmes etnográficos planejados e dirigidos em parceria (Vídeo nas aldeias, 2020), defesas de teses e dissertações contaram com interlocutoras como membros da banca (Flores, 2018), aulas e cursos foram oferecidos conjuntamente (Carvalho, 2019). E esses são alguns exemplos apenas, que ficam dentro dos produtos tipicamente exigidos pela academia. Fora dela, a regra é a assinatura coletiva de relatórios, publicações, políticas e eventos. Mas consideramos que o formato é novo na podosfera antropológica.

\footnotetext{
${ }^{8}$ Reconhecemos, claro, que esse contato pode acontecer com outros entes que não pessoas, não humanas. Ainda assim, é do contato - com arquivos históricos, substâncias, obras de arte, para ficar com alguns exemplos - que surge a possibilidade do diálogo e, portanto, de Antropologia.
} 


\section{Soraya Fleischer e Daniela Tonelli Manica}

Embora, desde 2019, tenham surgido muitos novos podcasts de Antropologia (Fleischer e Manica, 2020), o Mundaréu inclusive, ele é o único que, ao longo de seus episódios, adotou sistematicamente o encontro entre antropóloga e interlocutora como mote e meta. Embora a podosfera seja antiga e ampla, ainda falta uma presença mais consolidada de podcasts científicos (Kwok, 2019).

O nosso procedimento tem sido mapear uma antropóloga que tenha uma pesquisa em andamento, dirigir-lhe um primeiro convite e pedir que convide uma interlocutora. Esse segundo convite não parte de nós duas, como anfitriãs, mas da pesquisadora. Essa estratégia é fundamental para que chegue ao programa uma dupla que já existe a partir do diálogo. A nossa aposta não é aleatória, mas baseada na história que aquela dupla tem junta. Isto não quer dizer que as duas pessoas concordem com tudo, que haja convergência sobre todos os assuntos. Mas que terão intimidade e confiança mútua para poderem estar juntas na gravação e conversar, inclusive sobre os dissensos que já lhes acompanham ou que surgirem na conversa em estúdio.

Portanto, a presença dessa dupla tem sido a marca do Mundaréu nessas suas primeiras temporadas. Mais do que isso, é seu principal trunfo porque, a nosso ver, permite que muito seja discutido em termos epistemológicos sobre a Antropologia. Agora, queremos considerar se e como a ideia de "mutualidade" pode nos ajudar a compreender os efeitos da presença dessa díade especial.

\section{Mutualidade}

Fiamo-nos num conjunto de autores que foram reunidos numa coletânea recente, Mutuality: Anthropology's changing terms of engagement (Sanjek, 2015), para pensar o conceito. Também nos beneficiamos das ideias de João de Pina-Cabral (2013), mais ou menos da mesma época, e que bebe em outra literatura para também pensar o conceito. Além disso, Haraway (2016) também tem trabalhado numa direção similar com a proposta da simpoiese.

De modo geral, para Roger Sanjek, o organizador da coletânea, a mutualidade fomentaria "relações positivas com as pessoas que estudamos, com quem trabalhamos, sobre e para as quais escrevemos e com quem nos comunicamos mais amplamente" (2015: 2). 
Lembra que não é algo novo nem intrínseco à Antropologia, mas depende de uma decisão explícita sobre como construir as relações em nosso trabalho. Mutualidade pode significar o terreno comum, sobre o qual todas as partes envolvidas têm interesses, interpretações, esforços e ações, muitas vezes, mas não apenas, coincidentes (Hirabayashi, 2015: 119). Há dissensos, claro, mas que também são considerados como processos produtivos e potencialmente construtivos.

Catherine Besteman, outra autora do livro, aposta que a mutualidade gere solidariedade, colaboração e autotransformação para os dois lados. Segundo ela, muitas antropólogas, envolvidas com pesquisas de longo termo, chegam à conclusão de que a principal decorrência desses projetos não são necessariamente os "dados de pesquisa", mas as relações pessoais mutuamente construídas e marcam as duas biografias em jogo. Como qualquer outro relacionamento longo e porque nunca somos apenas tidas como colaboradoras intelectuais (mas também, eventualmente, amigas, parentes, vizinhas, testemunhas), esse tipo de relação também implica e enfrenta "tensões, ambivalências, ambiguidades, desapontamentos e rupturas" (Besteman, 2015: 264).

"Mutualidade envolve negociação" (Shield, 2015: 205) com tantas partes envolvidas e em tantos momentos e, por isso, não é uma relação para dentro da qual deslizamos naturalmente. A mutualidade é merecida e construída conjuntamente (Jacobs, 2015: 251) e exigida e definida especificamente por cada grupo com quem fazemos nossas pesquisas (Shield, 2015: 217). Por isso, entendemos que a "mutualidade é seletiva e fluida ao longo do tempo" (Rodriguez, 2015: 58), não é fixa, não é imutável. Acompanha as flutuações e delicadezas das relações per se. Precisa de tempo para se estabelecer, se desenvolver, respeitando os parâmetros locais de trocas e respeitando a personalidade e os limites das duas pontas, interlocutora e pesquisadora. Assim, se desejada, desenvolver a sensação de mutualidade é um "ato de paciência" (Wali, 2015: 177).

Rogaia Abusharaf aproxima a mutualidade da ideia de urgência para que "nossa posicionalidade como pesquisadoras seja interrogada, para suplantarmos o distanciamento e as outras 'ficções persuasivas da antropologia', como diria M. Strathern" (2015: 130). Orientar-se pela ética da mutualidade é trabalhar com e para a comunidade em questão, de acordo com suas demandas e litígios pela autodeterminação, resistência e sobrevivência. É, portanto, uma ferramenta que pode fazer da pesquisa algo social, ética e politicamente 


\section{Soraya Fleischer e Daniela Tonelli Manica}

informado. É uma Antropologia, acima de tudo, situada (Hirabayashi, 2015; Haraway, 1988). Por isso, para muitos, é o "modo ativista da colaboração" que acaba por definir a mutualidade (Wali, 2015: 174). Assim, a proposta das autoras reunidas nesta coletânea reforça que a mutualidade é uma escolha em pautar o trabalho antropológico com os valores de solidariedade e colaboração. É uma forma possível de fazer Antropologia, não a única. Nesta forma, a empatia, a paciência, a interpelação são aspectos definidos e negociados coletiva e paulatinamente para construir uma relação mútua.

Pina-Cabral também compreende que a relação antropológica acontece por vontade de ambas as partes e sobre um terreno comum. Para pensar esse terreno em um amplo sentido, ele considera, especialmente, os aspectos da atenção, da comunicação e da compreensão: “O etnógrafo e o informante não estão apenas trocando informações, eles estão atentos ao mundo juntos. Estar atento conjuntamente, entretanto, é um gesto que vai além da comunicação, uma vez que é um gesto formativo para a visão de mundo dos envolvidos. O desejo de ajudar a haver entendimento mútuo é parte e parcela do processo etnográfico" (2013: 6-7). Ao que parece, há um pressuposto hermenêutico em seu argumento, já que depende de espaços, desejos e atenções minimamente convergentes - o que ele chama de "gesto antropológico"para que a compreensão possa acontecer.

$\mathrm{O}$ autor foi muito inspirado no trabalho de J. Fabian que define a mutualidade etnográfica como "a promessa de compreensão não trivial que é produzida pelo pesquisador e pelo interlocutor conjuntamente" (Fabian, 1995: 47 apud Pina-Cabral, 2013: 2). E, partir dessa ideia de compreensão não trivial, "um aspecto inevitável de toda a interação da pesquisa de campo seria a ocorrência da sensação de revelação compartilhada. No nosso mundo atual, de globalização quase que instantânea, mais ainda do que no passado, a presença da etnógrafa em campo, assim como o que ela eventualmente vier a escrever sobre isso, tem um impacto no campo mas, mais do que isso, corresponde a processos de descoberta conjunta" (Pina-Cabral, 2013: 2, grifos nossos). Por isso, "o gesto etnográfico envolve uma forma de cooperação que é constitutiva dos interlocutores porque presume atenção conjunta" (ibid: 5, grifo nosso). Atenção, revelação e descoberta vão criando a ideia de "gesto antropológico" proposta pelo autor. Este gesto, de natureza tão específica, é o que depende do e, ao mesmo tempo, alimenta o valor da mutualidade. E, no Mundaréu, o propósito é trazer e compartilhar esse gesto mútuo na prática e em ação. 
Pina-Cabral lembra que essa atenção para o mundo não cessa com o final das atividades do trabalho de campo, mas perduram e alimentam a relação entre essas duas pessoas para além da pesquisa, para além da Antropologia. O interesse um pelo outro sustenta o laço e os diálogos subsequentes e, no Mundaréu, temos notado como as questões, que começaram como "de pesquisa", vão se transformando, adensando e ampliando para questões que dizem respeito à vida daquelas duas pessoas, seu trabalho de modo mais geral, sua atuação mais ampla no mundo. Pode até começar com uma troca de informações para um produto específico (uma dissertação de mestrado, uma tese de doutorado etc.), mas também pode ir passando a uma troca de impressões e reflexões - mutuamente influenciadas - sobre questões mais envolventes.

\section{Efeitos epistemológicos e pedagógicos: problematizando a confecção antropológica}

Parece haver dois grandes conjuntos de repercussões ao tomarmos a mutualidade como princípio norteador da Antropologia que fazemos no Mundaréu, um epistemológico e outro pedagógico. E ambos se retroalimentam continuamente.

Para Lane Hirabayashi (2015), a Antropologia realizada pelo princípio da mutualidade, seria, ao mesmo tempo, um ideal, um método de pesquisa, uma prática de pesquisa social e uma proposta epistemológica pelo fato de produzir conhecimento. Nesse mesmo sentido, para Joanne Rappaport, a colaboração é uma escolha aberta, deliberada e absolutamente transparente para o trabalho etnográfico.

A autora aposta noutro termo, mas com ressonância similar à mutualidade. A colaboração promove outras formas de pensar, analisar, teorizar e publicar. Essa abordagem “apresenta potencial para nutrir e revitalizar o pensamento antropológico" (Rappaport, 2008: 2). Ela sugere, por exemplo, que a colaboração estimula a criação conjunta, inclusive da ciência. "Há um vazio entre o diálogo com perguntas e respostas em uma direção de mão única, que caracteriza a etnografia em geral e os diálogos recíprocos, em que perguntas e respostas vêm dos dois lados num movimento bidirecional" (ibid: 8).

No Mundaréu, é isso que vemos acontecer, quando perguntas são colocadas por nós, anfitriãs, mas também pelas duas participantes, uma para outra e de volta para nós. Mais do que isso, ao privilegiarmos que a conversa comece com a interlocutora convidada, estamos 
"mudando o controle do processo de pesquisa para fora das mãos da antropóloga", contribuindo para que "dialoguemos com metodologias já escolhidas pela comunidade" e pela interlocutora (Rappaport, 2008: 8-9). São novas chaves de interpretação, novas prioridades propostas à escuta e, consequentemente, novas formas de analisar e comunicar resultados desse diálogo. A proposta da autora é a "co-teorização", que só revitalizaria a Antropologia.

Seguindo por esse caminho de Rappaport, a partir do pressuposto de que o que ocorre durante uma pesquisa antropológica tem uma natureza do "junto" e "compartilhado", autores como Pina-Cabral e Fabian também estão propondo que os resultados produzidos são coautorados. Do falar de fora e de longe, do falar sobre e além, com o formato do podcast Mundaréu, passamos ao falar com e a interlocutora tem a chance de ver como sua comunidade e suas opiniões são tratadas pela antropóloga que lá esteve a pesquisar. Essa ciência antropológica resultaria, portanto, não apenas do encontro entre esses dois mundos, mas da imbricação mútua desses dois mundos. Assim, a pergunta de pesquisa, a metodologia adotada para levá-la adiante, o tipo de texto escolhido para apresentar e divulgar resultados, tudo pode ser transformado por essa imbricação. Se Rappaport pensa em "colaboração", Pina-Cabral e os autores reunidos por Sanjek estão pensando em "mutualidade" - ambos caminhos que a Antropologia tem feito historicamente, mas sem necessariamente considerar a sua rentabilidade teórica. Ao considerarmos as sugestões destes autores, levar a sério a mutualidade e colocá-la no centro do debate, este movimento chacoalha epistemologicamente a Antropologia.

Na ponta pedagógica, parece impossível continuarmos fazendo pesquisa do jeito que aprendemos na escola, é impossível sustentar eticamente que apenas recolhamos e analisemos os materiais. As populações geralmente visitadas pela Antropologia, e as interlocutoras que visitaram o Mundaréu, têm nos cobrado por uma participação mais direta e ativa. O avesso da mutualidade pode ser, por exemplo, "as técnicas pedagógicas tradicionais de educação bancária e a pesquisa realizada de modo assimétrico, top-down e extrativista", em que a pesquisadora vai até a comunidade, coleta dados e depois desaparece (Rodriguez, 2015: 59).

Rodriguez e Sanjek acham que vivemos uma "crise de mutualidade", se continuamos a desenhar nossas pesquisas num espaço e depois somos interpeladas pelas prioridades de 
outro espaço, se insistimos na separação entre o ideal de objetividade que nos incumbe a universidade e o chamado ao engajamento feito pelas nossas interlocutoras (Rodriguez, 2015: 49), se privilegiamos acima de tudo o avanço profissional, o acesso e o direito ilimitados aos dados e o refinamento teórico da disciplina (Sanjek, 2015: 286). Rodriguez pergunta: e se mutualidade se tornasse o critério do desenho e da avaliação da qualidade de nossas pesquisas? (Rodriguez, 2015: 49). E Sanjek pergunta se devemos mesmo manter a teoria e a publicação como os únicos commodities acadêmicos (Sanjek, 2015: 292-293). Imaginamos, a partir dessas provocações, toda uma interessante cascata de mudanças sobre as esferas de formação, financiamento, publicação e empregabilidade das antropólogas.

A mutualidade torna injustificável, portanto, a metodologia "mosca-na-parede" (porque não podemos mais ficar dentro do armário com a nossa posicionalidade), a narrativa onisciente e altiva (porque nossas interlocutoras e leitoras não nos perdoarão de uma aura de superioridade), a discursividade "lacradora" (porque definitivamente não conhecemos a totalidade dos fatos), a publicação exclusivamente teórica e abstrata (porque nos serão exigidas traduções e aplicações), o discurso do sujeito abstrato (porque somos, antes de tudo, um corpo presente com idade, cor, sexo, sentimentos e desejos).

$\mathrm{O}$ valor da mutualidade entende pesquisa de outra forma, exige outro tipo de pesquisadora, transforma de onde viemos e para onde vamos como antropólogas. Critica, definitivamente, a prática extrativista e questiona que continuemos fazendo etnografias "hit and run" (ou, bate e sai correndo), escrevendo textos antropológicos pouco amistosos para leitores não acadêmicos, sustentando o carimbo de "tolas esclarecidas" (Sanjek, 2015: 291; 294). Por isso tudo, pensar pela lente da mutualidade revira várias das práticas consolidadas da socialização acadêmica e da produção científica, impactando diretamente os nossos cânones teóricos, metodológicos, éticos.

Ainda em termos pedagógicos, tomar a mutualidade como valor a ser cultivado promove toda uma inversão epistemológica de quem produz e consome a ciência. Por exemplo, o professorado será igualmente encontrado fora das universidades, nas comunidades onde a pesquisa acontecer; a voz e versão da pesquisadora passa a ser mais uma: mais uma expert dentre tantas, mais uma autora entre várias; vai assumindo papeis mais periféricos, vira tradutora, editora, educadora, escutadora (Fienup-Riordan, 2015: 76). Vira 


\section{Soraya Fleischer e Daniela Tonelli Manica}

uma urgente amplificadora das vozes (Abusharaf, 2015: 140), assumindo "papeis prismáticos" (ibid: 150).

O Mundaréu pretende traduzir e discutir para estudantes em início de carreira o que faz e como trabalha a Antropologia, cumprindo uma função de formação profissional. Mas, também, se desdobra em uma atividade de extensão, importante nesse momento em que as Ciências Humanas têm sido abertamente questionadas e invalidadas como campo científico. Para conseguirmos fazer uma antropologia pública no Mundaréu, seguindo princípios da mutualidade, a linguagem e o foco precisam mudar. Precisamos falar de uma forma mais acessível, informal e amistosa (Rappaport, 2008: 1), em um português com menos jargão acadêmico, para facilitar a compreensão de quem não conhece a Antropologia nem a universidade (Abusharaf, 2015: 136-137). Não é uma tarefa fácil, sobretudo quando a socialização acadêmica tiver sido muito intensa e/ou extensa. Como diz Susan Lobo, ao falar sobre seu processo de construção de uma narrativa engajada para fora do espaço acadêmico: “precisei aprender, desaprender e reaprender (...) a escrever em uma variedade de estilos, muitas vezes evitando e desfazendo a formalidade e o enrijecimento da escrita acadêmica que tão bem tinha nutrido durante o treinamento acadêmico" (Lobo, 2015: 200).

O Mundaréu tem concentrado seu foco nas histórias que são contadas pela dupla - a interlocutora e a sua antropóloga -, vividas dentro e fora do trabalho de campo. Kirin Narayan sugere que a acessibilidade às nossas ideias da Antropologia acontece pela presença das histórias: "É mais do que urgente que antropólogos reconheçam que são as pessoas e não fantoches teóricos que populam nossos textos" (1993: 680). Não apenas a descrição de cenas, diálogos e encontros, mas também que essas narrativas - e a sua construção - sejam vocalizadas em primeira pessoa. E que as histórias sejam contadas não em sua forma mais usual, a escrita, nem reforçando o "grafocentrismo" (Günther, 2013), mas vivificadas com a oralidade, os sotaques, as cadências e as emoções das narradoras.

No podcast, a ideia é passar da narrativa que, tão frequentemente, reproduz abstrações conceituais, para a narrativa de histórias situadas. Trazer as interlocutoras para dentro do estúdio é uma forma de registrar outras memórias e interpretações sobre o trabalho das antropólogas, sobre o encontro entre as duas. É pensar na produção mais polifônica de textos e registros sobre a Antropologia, como outros antropólogos (Silva, 2000) e historiadores (Vieira, 2020) têm nos sugerido faz algum tempo. 


\section{Apontamentos finais}

Ao fazer um desenho muito específico para seus episódios, o Mundaréu está enfatizando a relação como elemento fundante da realização do empreendimento de pesquisa na Antropologia. Tanto a relação entre duas anfitriãs, pesquisadoras da área trabalhando juntas, mas sobretudo a relação entre as duas convidadas, que se conhecem e aprofundam o laço ao longo da pesquisa antropológica, e para além dela. Estamos apostando que essa relação pode ter vários aspectos e um deles é justa e prioritariamente a mutualidade.

Apostar num formato que evidencie a mutualidade, como um dos princípios fundantes da relação que pesquisadoras estabelecem com as pessoas durante suas pesquisas antropológicas, é optar por abrir os bastidores da Antropologia. A ideia do Mundaréu é revelar o que é central para que a Antropologia possa acontecer, mas que em geral fica em plano secundário, desprivilegiado e pouco discutido nos textos publicados pela área. É deixar transparecer - junto com as pessoas que conhecemos durante nossos trabalhos de campo - o modus operandi da Antropologia e o modus operandi que as duas pontas - quando se aproximam - desejam colocar em prática.

Além disso, esperamos ajudar a vocalizar e, sobretudo, a rever porque a Antropologia existe e como ela opera no mundo. Além de convidar as pessoas que realizam as pesquisas e apresentar seus resultados, também queremos discutir as formas e relações que tornaram tudo isso possível. Ao provocar suas entranhas epistemológicas e pedagógicas, esperamos estar contribuindo para tornar a Antropologia mais pública e aberta, colaborando para a construção de futuros múltiplos e plurais, nos quais sejam legítimas e cultiváveis a diversidade de perspectivas e formas de viver.

\section{REFERÊNCIAS}

ABUSHARAF, Rogaia Mustafa. Cartographies of mutuality: Lessons from Darfur. In SANJEK, Roger (org.). Mutuality. Anthropology's changing terms of engagement. Philadelphia: University of Pennsylvania Press, 2015, pp. 130-152. 


\section{Soraya Fleischer e Daniela Tonelli Manica}

BESTEMAN, Catherine. On ethnographic love. In: SANJEK, Roger (org.). Mutuality. Anthropology's changing terms of engagement. Philadelphia: University of Pennsylvania Press, 2015, pp. 259-284.

CARVALHO, José Jorge de. "Uma conversa com José Jorge de Carvalho". Saberes tradicionais - UFMG, 2019. Disponível em https://www.saberestradicionais.org/umaconversa-com-jose-jorge-de-carvalho/. Acesso em: 23 nov. 2020

CLIFFORD, James. A experiência etnográfica: Antropologia e Literatura no século XX. Rio de Janeiro: Editora da UFRJ, 1998.

FIENUP-RIORDAN, Ann. 'If you want to go fast, go alone. If you want to go far, go together': Yup'ik elders working together with one mind. In: SANJEK, Roger (org.). Mutuality. Anthropology's changing terms of engagement. Philadelphia: University of Pennsylvania Press, 2015, pp. 61-80.

FLEISCHER, Soraya e COUTO, Julia. Mundaréu: Um podcast de Antropologia, uma ferramenta polivalente. GIS - Gesto, Imagem, Som - Revista de Antropologia, no prelo.

FONSECA, Claudia e GARRIDO, Rodrigo. Os limites do humano: restos humanos em um laboratório de genética forense. In: Interseções. Revista de Estudos Interdisciplinares, UERJ. v. 20 n. 1, p. 14-35, jun. 2018.

FLEISCHER, Soraya e MANICA, Daniela. Ativando a escuta em tempos pandêmicos. In: Boletim da Anpocs "Ciências sociais e o Coronavírus" 78, ANPOCS, 07/07/2020.

FLORES, Luiza Dias. Ocupar: composições e resistências kilombolas. Tese [Doutorado em Antropologia Social]. Rio de Janeiro: MN/UFRJ, 2018. 
GUÉRIOS, Paulo Renato. Pesquisa Participativa e Julgamento dos Interlocutores: uma reflexão a partir de pesquisas em Antropologia Visual. In: Ilha. Revista de Antropologia, v. 17, n. 1, p. 117-141, jan./jul. 2015.

GÜNTHER, Luisa. Experiências (des)compartilhadas: arte contemporânea e seus registros. 402 f., il. Tese [Doutorado em Sociologia]. Brasília: Universidade de Brasília, 2013.

HARAWAY, Donna. Situated knowledges: the science question in feminism and the privilege of partial perspective. Feminist Studies 14(3), 1988, pp.575-599.

. Staying with the trouble: making kin in the Chthulucene. Durham and London: Duke University Press, 2016.

HIRABAYASHI, Lane Ryo. Thinking about and experiencing mutuality: Notes on a son's formation. In SANJEK, Roger (org.). Mutuality. Anthropology's changing terms of engagement. Philadelphia: University of Pennsylvania Press, 2015, pp. 118-129.

JACOBS, Lanita. On 'making good' in a study of African American children with acquired and traumatic brain injuries. In SANJEK, Roger (org.). Mutuality. Anthropology's changing terms of engagement. Philadelphia: University of Pennsylvania Press, 2015, pp. 249-258.

KOPENAWA, Davi e ALBERT, Bruce. A queda do céu. Palavras de um xamã yanomami. São Paulo: Companhia das Letras, 2015.

KWOK, Roberta. Listen up. In: Nature 565, 2019, pp. 387-389.

LOBO, Susan. Why? And how? An essay on doing. In SANJEK, Roger (org.). Mutuality. Anthropology's changing terms of engagement. Philadelphia: University of Pennsylvania Press, 2015, pp. 191-202. 
MANICA, Daniela; GOLDENBERG, Regina; e ASENSI, Karina. CeSaM, as células do sangue menstrual: gênero, tecnociência e terapia celular. Interseções: Revista de Estudos Interdisciplinares, UERJ. v. 20, 2018. p. 93-113.

MUNDARÉU. Entrevistadoras: Daniela Manica e Soraya Fleischer. Podcast. Disponível em: https://mundareu.labjor.unicamp.br/ Acesso em: 30 nov. 2020.

NARAYAN, Kirin. How native is a 'native' anthropologist?. American Anthropologist 95, 1993, pp. 671-686.

PINA-CABRAL, João. The two faces of mutuality: Contemporary themes in Anthropology. In: Anthropological Quarterly 86(1), 2013, pp. 257-276.

RAPPAPORT, Joanne. Beyond participant observation: Collaborative ethnography as theoretical innovation. In: Collaborative Anthropology 1, 2008, pp. 1-31.

RODRIGUEZ, Sylvia. Mutuality and the field at home. In SANJEK, Roger (org.). Mutuality. Anthropology's changing terms of engagement. Philadelphia: University of Pennsylvania Press, 2015, pp. 45-60.

SANJEK, Roger (org.). Mutuality. Anthropology's changing terms of engagement. Philadelphia: University of Pennsylvania Press, 2015.

SHIELD, Renée R. Embedded in time, work, family and age: A reverie about mutuality. In SANJEK, Roger (org.). Mutuality. Anthropology's changing terms of engagement. Philadelphia: University of Pennsylvania Press, 2015, pp. 203-224.

SILVA, Wagner Gonçalves da. O antropólogo e sua magia: trabalho de campo e texto etnográfico nas pesquisas antropológicas sobre as religiões afro-brasileiras. São Paulo, Edusp, 2000. 
VIDEO NAS ALDEIAS. http://www.videonasaldeias.org.br/2009/. Acesso em: 23 nov. 2020.

VIEIRA, Antonio Otaviano. O direito de fala e de memória na epidemia. Boletim Cientistas Sociais $e$ o Coronavírus. Anpocs, 2020. Disponível em: http://anpocs.org/index.php/publicacoes-sp-2056165036/boletim-cientistas-sociais/2344boletim-n-30-cientistas-sociais-e-o-coronavirus?idU=3. Acesso em: 23 nov. 2020.

WALI, Alaka. Listening with passion: A journey through engagement and exchange. In: SANJEK, Roger (org.). Mutuality. Anthropology's changing terms of engagement. Philadelphia: University of Pennsylvania Press, 2015, pp. 174-190.

Recebido: 19/12/2020 Aprovado: 05/02/2021 